Jurnal Pemberdayaan: Publikasi Hasil Pengabdian kepada Masyarakat

Vol. 2, No. 3, Desember 2018, Hal. 413-420

ISSN: 2088 4559; e-ISSN: XXXX-XXXX

DOI:

\title{
PENDAMPINGAN PENGELOLAAN WEBSITE SEKOLAH MUHAMMADIYAH DI KOTA YOGYAKARTA
}

\author{
Mushlihudin $^{1}$, Tedy Setiadi ${ }^{2}$, Wahyu Pujiyono ${ }^{3}$ \\ Universitas Ahmad Dahlan, Yogyakarta ${ }^{1,2,3}$ \\ Email: mushlihudin@tif.uad.ac.id ${ }^{1}$
}

\begin{abstract}
ABSTRAK
Penerapan teknologi informasi di sekolah salah satunya pengadaan website sekolah sebagai media penyebaran informasi dan komunikasi antara sekolah dengan pihak terkait. Dengan adanya website sekolah terdapat beberapa manfaat antara lain turut hadir dalam memberikan konten-konten positif bagi publik untuk mewujudkan internet sehat, mendorong sekolah menghadirkan informasi kegiatan sekolah yang positif dan kreatif, wali siswa dan masyarakat dapat mengetahui berbagai hal tentang sekolah secara langsung, dan menumbuhkan kepercayaan masyarakat kepada sekolah. Kota Yogyakarta terdapat banyak sekolah baik negeri negeri maupun swasta. Sekolah Muhammadiyah merupakan sekolah swasta di Kota Yogyakarta yang berjumlah 58 sekolah. Permasalahannya beberapa sekolah yang belum memperhatikan penulisan berita dengan baik. Tujuan kegiatan ini untuk mendampingi para pengelola website dalam penulisan berita yang baik agar mudah dicari oleh mesin pelacak dan menarik para pembaca. Harapan pendampingan agar website dapat dilacak menggunakan mesin pelacak dan tampil dihalaman pertama. Pelaksanaan pendampingan dengan melakukan pelatihan dan praktel tentang pembuatan berita yang baik, pengolahan media dan penerapan teknik SEO pada website. Pasca pelaksanaan kegiatan dilakukan evaluasi pada bulan keenam dan didapatkan hasil sebanyak 19 sekolah dapat dicari dengan mesin pelacak Google dan tampil di halaman pertama.
\end{abstract}

Keywords: website sekolah, konten positif, internet sehat, Search Engine Optimization.

\begin{abstract}
The application of information technology in schools is one of which provides school websites as a medium for disseminating information and communication between schools and related parties. With the existence of a school website there are several benefits including being present in providing positive content for the public to create a healthy internet, encouraging schools to present positive and creative information on school activities, guardians of students and the community can know various things about schools directly, and grow public trust in the school. The city of Yogyakarta has many schools both public and private. Muhammadiyah School is a private school in the city of Yogyakarta, which amounts to 58 schools. The problem is that some schools have not paid attention to news writing properly. The purpose of this activity is to assist website managers in writing good news to be easily searched by tracking machines and attracting readers. The expectation of assistance so that websites can be tracked using a search engine and appear on the first page. Implementation of assistance by conducting training and practice on making good news, processing media and implementing SEO techniques on the website. After the implementation of the activity carried out an evaluation in the sixth month and obtained as many as 19 schools can be searched with Google tracking machines and appear on the first page.
\end{abstract}

Keywords: school websites, positive content, healthy internet, Search Engine Optimization. 


\section{PENDAHULUAN}

Penerapan teknologi di sekolah salah satunya dengan memanfaatkan teknologi informasi sebagai media komunikasi antara sekolah dengan pihak pemangku kepentingan yang terkait dengan berupa website sekolah. Adanya website sekolah maka pihak sekolah akan mendapatkan beberapa manfaat antara lain turut hadir dalam memberikan konten yang positif bagi publik, berperan aktif untuk mewujudkan internet sehat, mendorong sekolah menghadirkan informasi kegiatan sekolah yang positif dan kreatif, wali siswa dan masyarakat dapat mengetahui kegiatan dan perkembangan tentang sekolah secara langsung, serta menumbuhkan kepercayaan masyarakat kepada sekolah.

Kota Yogyakarta memiliki banyak perguruan tinggi dan sekolah baik negeri maupun swasta. Jumlah sekolah Muhammadiyah di Kota Yogyakarta ada 58 sekolah meliputi SD, SMP, MTs, SMA dan SMK, dengan rincian 11 sekolah untuk tingkat SLTA (SMA/SMK), 12 sekolah untuk tingkat SLTP (SMP/MTs), dan 35 sekolah untuk tingkat SD. Dengan adanya perkembangan teknologi informasi yang semakin baik dan murah merupakan keuntugan bagi sekolah. Keberadaan website sekolah yang baik dapat berfungsi sebagai pusat informasi dan komunikasi antara sekolah dengan pihak terkait. menjadi sangat penting.

Permasalahan yang terjadi dari 58 sekolah, yang memiliki website ada 44 sekolah dan yang tidak memiliki 14. Sedangkan untuk memiliki website sebanyak 42 memiliki website yang dapat diakses dan 2 website tidak dapat diakses.. Ditinjau berdasarkan status domain yang digunakan oleh sekolah terbagi menjadi dua yaitu yang menggunakan domain resmi Indonesia (sch.id) sejumlah 36 sekolah dan domain gratis (blogspot dan wordpress) sebanyak 8 sekolah. Permasalahan lain yaitu beberapa sekolah masih belum memperhatikan tentang pentingnya memanfaatkan website sebagai media komunikasi dan publikasi yang efektif kepada masyarakat. Hal ini bisa dilihat dari seberapa kepedulian pengelola website sekolah untuk memutahirkan isi atau berita yang tampil di website. Sekolah yang melakukan pemutakhiran berita pada bulan terakhir saat pengamatan terdapat 4 website sekolah. Sekolah yang melakukan update berita 2-3 bulan sebelum bulan pengamatan sebanyak 12 sekolah. Sekolah yang melakukan pemutakhiran berita pada bulan 4-5 bulan pengamatan sebanyak 11 sekolah. Sekolah yang melakukan pemutakhiran berita pada bulan 6-10 sebelum bulan pengamatan sebanyak 9 sekolah. Sekolah yang melakukan pemutakhiran berita pada bulan 11 bulan sebelum bulan pengamatan (hampir setahun) sebanyak 6 sekolah. Adapun website sekolah tidak bisa dibuka dan diduga sedang dalam serangan hacker sebanyak 2 sekolah. 
Kegiatan pengabdian masyarakat ini akan memberikan solusi terhadap permasalahan tersebut yaitu melakukan pendampingan kepada pengelola website yang tidak melakukan pemutakhiran website lebih dari 2 bulan.

Tujuan kegiatan pengabdian masyarakat ini yaitu meningkatkan pemahaman kepada pengelola website sekolah terkait isi berita, media yang ditampilkan dan teknik pengelolaan yang memenuhi kaidah SEO. Sehingga para pengelola website dapat memutakhirkan berita di website dengan kadiah yang sesuai dengan kaidah SEO dan website sekolah dengan mudah dicari oleh masyarakat melalui mesin pelacak. Pada akhirnya sekolah akan dikenal oleh masyarakat dan sekolah memiliki media media promosi yang murah dan mudah serta berlangsung selama sehari 24 jam, dan 7 hari sepekan.

Harapan dengan kegiatan ini, dapat membantu par apengelola website sekolah untuk menyajikan berita dan informasi sekolah dengan baik dan benar. Sehingga website sekolah dapat dilacak oleh mesin pelacak dan tampil di halaman pertama sehingga mudah dibaca dan menjadi pusat rujukan yang menarik oleh pihak manapun terkait sekolah. Terkait dengan ini maka setiap sekolah akan dituntut membuat dan memperbaiki dalam berbagai kegiatan agar menjadi sumber berita karena akan menyangkut kebenaran isi berita yang dipublikasikan melalui website.

\section{METODE}

Solusi yang ditawarkan dalam program pengabdian masyarakat ini yaitu "Pelatihan pembuatan berita website yang baik dan benar serta menarik bagi pembaca". Sebelum pelatihan dilaksanakan terlebih dahulu dilakukan penjajagan pemahaman dan kemampuan peserta terkait dengan materi yang akandisampaikan. Penjajagan dilakukan dengan cara mengerjakan kuisioner yang berisi tentang hal-hal penting dalam materi-materi yang akan diajarkan. Kuisioner dibuat secara online dan diberikan sepekan sebelum pelatihan dilaksanakan. Langkah penjajagan dilakukan untuk mengetahui materi seperti apa yang harus diberikan. Demikian juga untuk mempersiapkan bahan pelatihan agar hasilnya maksimal.

Materi pelatihan dibagi menjadi 3 bagian yaitu tentang cara menulis berita, pengambilan dan pengelolaan gambar, dan pemutakhiran berita dengan penerapan kaidah SEO.

Materi penulisan berita dijelaskan tentang unsur-unsur berita yang baik dan cara menuliskannya menjadi berita sekolah dalam website. Peserta diberi penjelasan tentang maksud unsur-unsur tersebut dan ditunjukkan contoh berita yang benar. Selanjutnya peserta diminta membuat berita yang mengikuti unsur-unsur tersebut. Disamping itu dilakukan juga praktek menganalisa berita-berita yang ada di internet. Akhir dari pelatihan tersebut peserta Pendampingan Pengelolaan Website Sekolah Muhammadiyah (Mushlihudin) | 415 
akan diberi tugas akhir yang harus dikerjakan selama 30 menit. Tugas akhir ini merupakan upaya untuk mengukur seberapa pemahaman yang diserap oleh peserta pelatihan.

Materi pengolahan gambar dijelaskan cara pengambilan gambar dengan kamera digital dan smartphone, cara pengolahan gambar meliputi pemotongan gambar, dan pengaturan pencahayaan serta kegelapan serta kekontrasan warna. Pada materi ini peserta dijelaskan tata cara pengambilan gambar yang dapat digunakan untuk ditampilkan dalam website. Gambar yang baik maka akan mendukung berita yang baik dan meningkatkan pemahaman pembaca terhadap isi berita. Setelah diberi penjelasan tentang teknik pengambilan gambar, peserta diajak keluar ruangan dan praktek berburu obyek yang dapat dijadikan sebagai bahan pendamping berita. Hasil pengambilan gambar kemudian diolah dengan menggunakan aplikasi komputer photoscape. Aplikasi untuk untuk memperbaiki hasil pengambilan gambar yang tidak maksimal. Dengan aplikasi ini beberapa pekerjaan yang dapat dilakukan antara lain, memotong gambar, menurunkan resolusi, mengatur pencahayaan dan ketajaman gambar. Harapan dari pelatihan ini yaitu gambar yang dipublikasikan dalam berita memiliki nilai dan dapat memberikan penjelasan agar berita dipahami oleh pembaca menjadi lebih baik. Dengan pengaturan fokus gambar dan tampilan yang baik akan menambah pembaca menjadi lebih berminat dan semangat dalam membaca berita.

Sebelum penyampaian materi peserta diberi tes awal sebagai penjajagan pemahaman dasar peserta. Selanjutnya dijelaskan tentang cara menerapkan kaidah SEO pada website. Disamping penjelasan peserta diminta untuk mempraktekkan penerapan kaidah pada sebuah berita yang akan dipublikasikan. Pelatihan sistem pengelolaan isi berita menggunakan WordPress dan ditunjukkan bagian-bagian yang penting untuk menerapkan kaidah SEO pada sebuah berita. Peserta diminta untuk menerapakan materi berita dan materi menampilkan gambar. Harapan yang didapat dengan pelatihan penerapan kaidah SEO yaitu untuk mengatur berita yang dipublikasikan agar dapat dengan mudah dicari dengan menggunakan mesin pelacak dan tampil di halaman pertama. Sehingga berita mudah ditemukan dan semakin banyak dibaca oleh pengguna dan masyarakat yang mencari berita sesuai kriteri yang terkandung dalam berita.

Dalam kegiatan ini semua pelatihan dilakukan dengan ceramah, praktek langsung dan disertai dengan diskusi. Untuk mempermudah peserta dalam melakukan latihan, setiap peserta diberi modul yang dapat digunakan untuk belajar setelah pelatihan selesai. Daimping itu juga disertai adanya pendamping atau asisten pelatihan yang mendampingi perserta selama pelatihan. 


\section{HASIL, PEMBAHASAN DAN DAMPAK}

Kegiatan ini dimulai dengan melakukan koordinasi pelaksanaan dan proses kegiatan terlihat pada gambar 1. Disamping koordinasi juga pengarahan kepada tim dalam perancangan materi dan tata tertib pelaksanaan, namapk pada gambar 2. Pelaksanaan kegiatan dilakukan di Laboratorium Komputer Dasat Teknik Informatika Universitas Ahmad Dahlan selama 3 hari, dimana dalam satu hari merupakan satu materi dalam pelatihan dan praktek selama 7 jam.

Hari pertama, pelatihan dan praktek penyajian berita yang baik, nampak pada gambar 3. Penekanan dalam materi ini yaitu membuat berita yang baik dan dapat dipercaya. Berita merupakan sesuatu yang telah diolah melalui bahasa dan teknik tertentu dari peristiwa yang merupakan kejadian aktual objektif. Berita adalah informasi aktual tentang fakta-fakta dan opini yang menarik perhatian orang (Kusumaningrat, 2010). Pengelola web sekolah sering dituntut memiliki peran ganda yaitu sebagai reporter dan sebagai admin web. Sebagai seorang reporter, penulis harus mampu mencari data-data kongkrit dilapangan dengan metode $5 \mathrm{~W}+1 \mathrm{H}$ (What, Who, Where, When, Why+How). Semakin lengkap data-data tersebut di peroleh, semakin baik pula isi berita yang akan di buat (Lanang, 2010). Metode penyampaian materi yaitu ceramah, dialog dan disertai dengan latihan serta pengamatan berita online. Peserta diajak untuk membuka berita di internet dan menguraikan unsur-unsur $5 \mathrm{~W}+1 \mathrm{H}$ yang terkandung dalam berita.

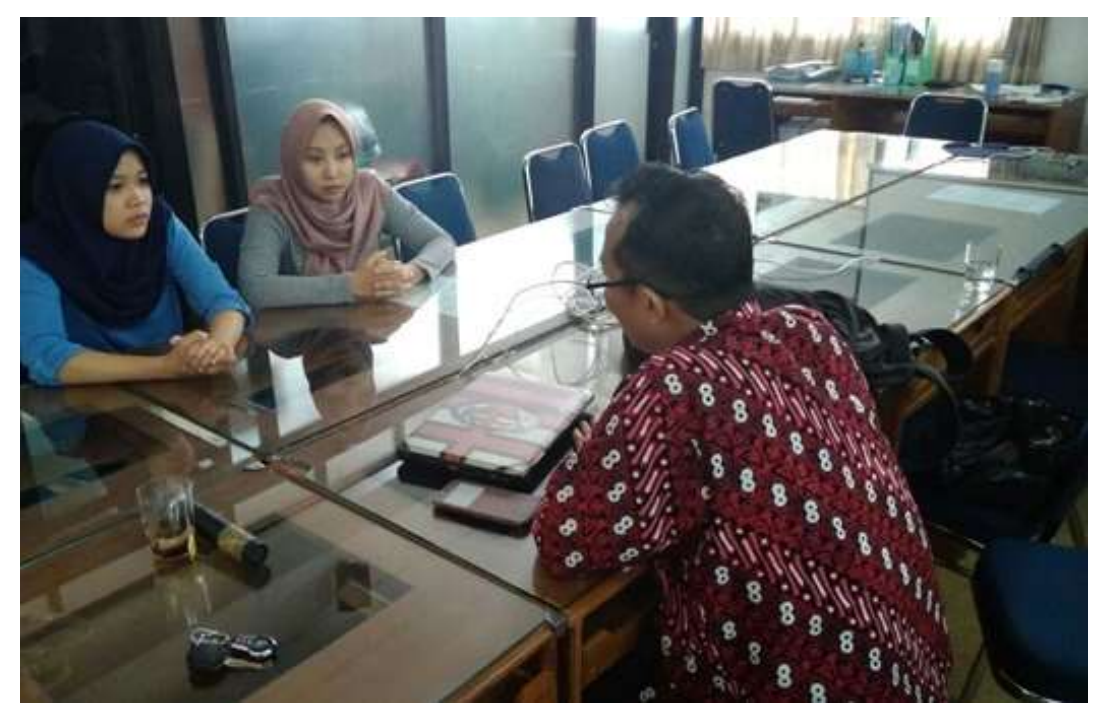

Gambar 1. Koordinasi pelaksanaan. 


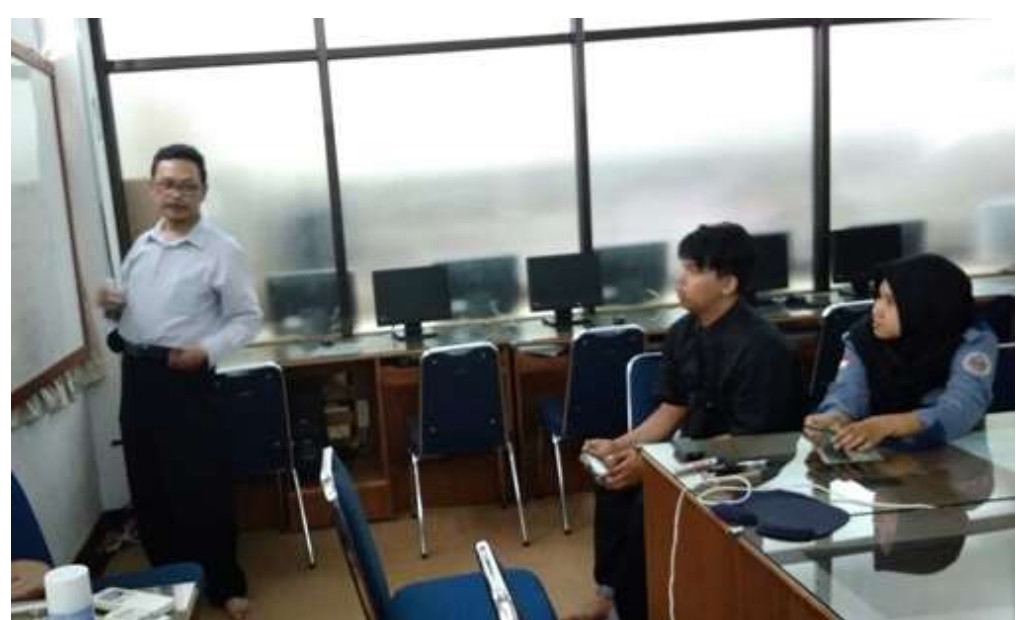

Gambar 2. Pengarahan dan perancangan materi.

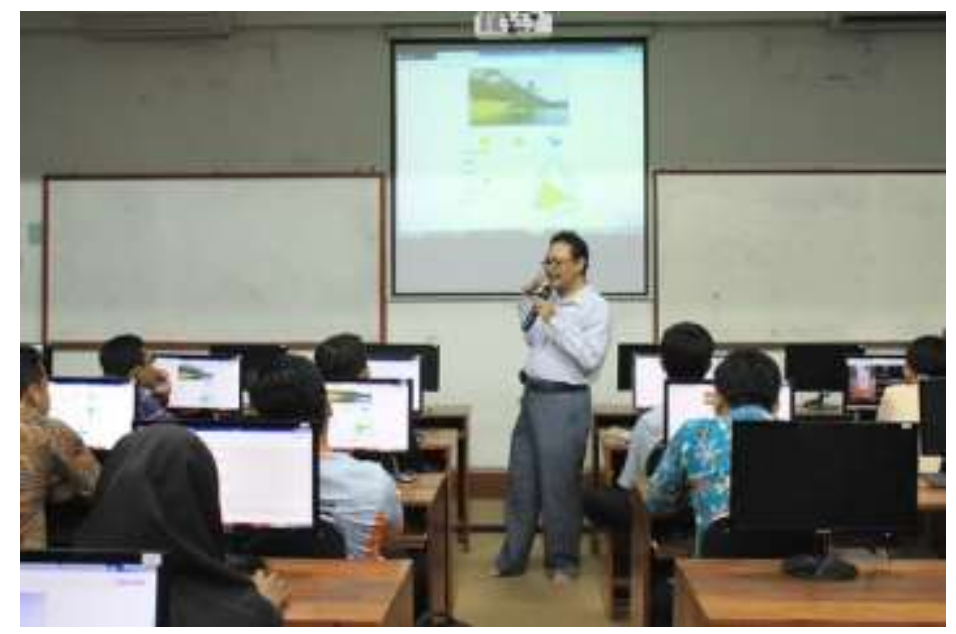

Gambar 3. Penyampaian materi

Hari Kedua, pelatihan teknik pengambilan gambar dan edit gambar. Hal yang membuat web menjadi sesuatu yang unik adalah dalam hal kemudahan informasi, juga penyajiannya berupa teks yang dilengkapi warna, gambar, suara, dan video (Stanley, 2010).

Pengambilan gambar disampaikan teknik pengambilan gambar yang dapat memberikan penjelasan berita. Sudut pengambilan gambar, fokus gambar yang akan diambil dan pencahayaan yang harus dipilih. Disamping penyampaian materi juga diserta contoh pengambilan gambar menggunakan camera digital dan smartphone yang baik. Peserta diajak jalan-jalan ke luar ruangan untuk mencari obyek gambar yang dapat dijadikan berita, nampak pada gambar 4 . 

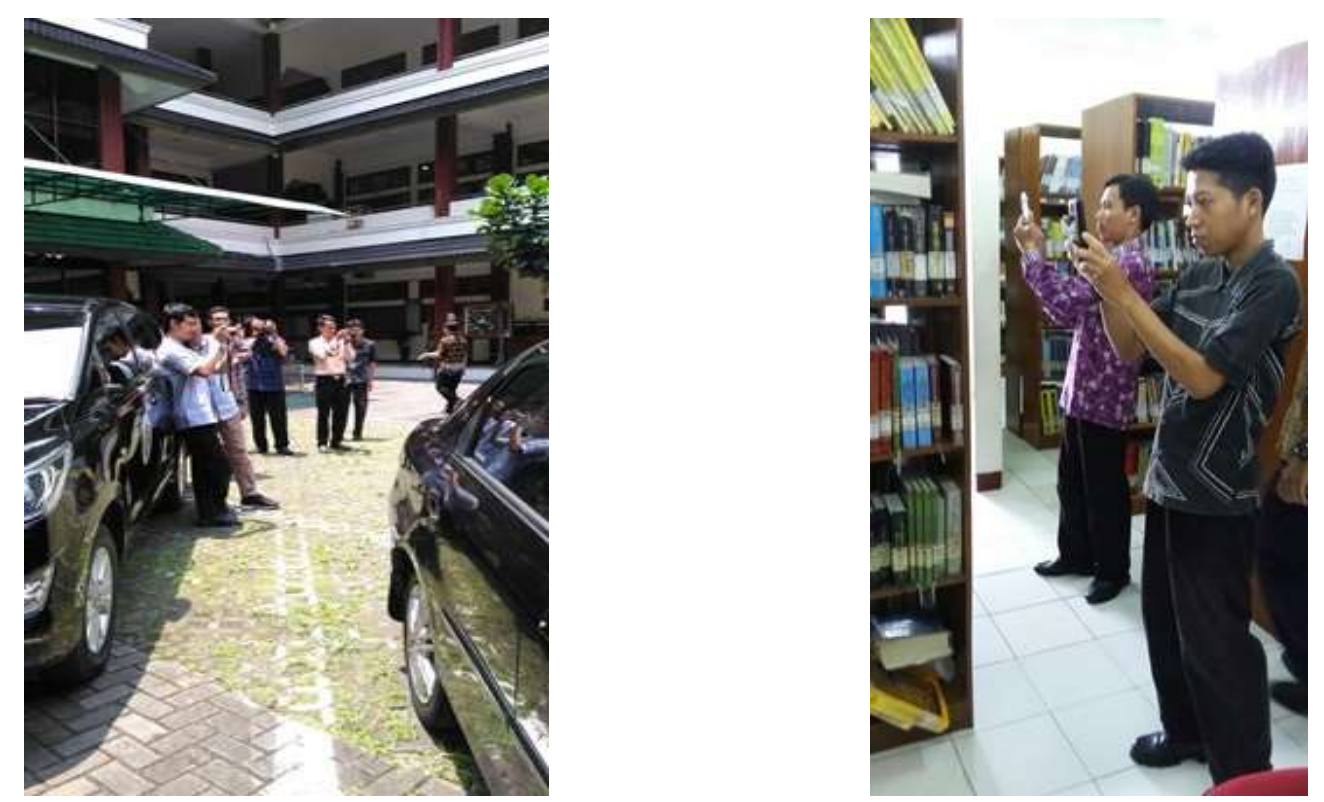

Gambar 4. Praktek pengambilan gambar dengan camera digital dan smartphone

Hari Ketiga, Pelatihan Pengelolaan Meta data dengan penerapan teknik SEO serta membuat link dan sharing ke media sosial. SEO adalah serangkaian proses yang dilakukan secara sistematis dan bertujuan untuk meningkatkan volume serta kualitas trafik kunjungan melalui mesin pencari menuju situs website tertentu dengan memanfaatkan algoritma mesin pencari tersebut, yang disebut dengan PageRank. Tujuan dari SEO adalah menempatkan sebuah situs website pada posisi teratas hasil pencarian berdasarkan kata kunci tertentu yang ditargetkan. Situs web yang menempati posisi teratas pada hasil pencarian memiliki peluang lebih besar untuk mendapatkan pengunjung. (Hernawati. 2013)

Pada sesi ini dijelaskan mengenai manfaat SEO terhadap jumlah kunjungan ke website. Salah satu tujuan website dikembangkan adalah untuk menyampaikan informasi ke masyarakat. Jika jumlah kunjungan masyarakat kurang maka informasi tidak tersebar dengan baik. Sesi ini peserta diajak untuk membuat Tag Heading, menentukan kata kunci, Judul dan Isi yang memiliki kaidah SEO, penulisan Metadata pada website, dan yang tidak tertinggal cara membuat link ke media sosial.

Pelatihan dilaksanakan selama 3 hari, selanjutnya akan dilakukan pendampingan dalam pengiriman berita ke website secara nyata. Peserta diminta untuk menyampaikan alamat website yang dikelola oleh masing-masing sekolah. Pasca pelaksanaan pelatihan dan pendampingan di kelas, dilanjutkan dengan pengamatan dan evaluasi terhadap website sekolah. Setelah 6 bulan selesai pelatihan, dilakukan evaluasi SEO terhadap website sekolah peserta pelatihan yang memiliki nama domain resmi dengan aplikasi bantu Google Lighthouse. Berdasarkan hasil pengamatan didapatkan hasil sebanyak 19 sekolah telah dapat 
dicari dan tampil di halaman pertama pada mesin pelacak google, dan 9 website diantaranya tampil di halaman paling atas sedangkan yang lain tampil di baris kedua atau lebih. Hal ini dapat dicapai karena berita yang publikasikan memiliki konten yang menarik untuk dibaca dan memenuhi kriteria SEO sehingga mesin pelacak mengenalinya dengan baik.

\section{SIMPULAN}

Kegiatan pelatihan dan pendampingan ini telah membantu beberapa Sekolah Muhammadiyah di Kota Yogyakarta memenuhi harapan yaitu website dapat dilacak di mesin pelacak dan tampil di halaman pertama. Untuk program selanjutnya dapat dilanjutkan dengan pelatihan dan pendampingan untuk sekolah-sekolah yang belum berhasil agar bisa memiliki hasil terbaik.

\section{DAFTAR PUSTAKA}

Kusumaningrat H., Kusumanigrat P.2009, Jurnalistik Teori dan Praktik, PT Remaja Rosdakarya, Bandung, hal.40.

Lanang Febria Galing Gumilang, 2010, Proses Kerja Reporter Berita Detikhot Subkanal Music Di Detik.Com Jakarta, Laporan Hasil Penelitian, Universitas Negeri Sebelas Maret, Surakarta.hal.44.

Stanley J. Bouran, 2004, Introduction to Mass Communication, Media Literacy and Culture. MC Graw Hill, third edition, USA, p275.

Fokus, 2017, Media Komunikasi dan Inspirasi :Jendela, edisi XIX Desember. Jakarta.

Hernawati, Kuswari., Optimalisasi SEO (Search Engine Optimizer) sebagai upaya meningkatkan unsur Visibility dalam Webometric, 2013, Prosiding, Seminar Nasional Matematika dan Pendidikan Matematika, UNY, 2009

\section{UCAPAN TERIMA KASIH}

Kami mengucapkan terima kasih kepada LPPM Universitas Ahmad Dahlan yang telah mendanai kegiatan ini dan Pimpinan PDM Kota Yogyakarta beserta staff yang telah mendukung kegiatan ini. 